\title{
EU Liaison Officer Supports Top-Quality Materials Research
}

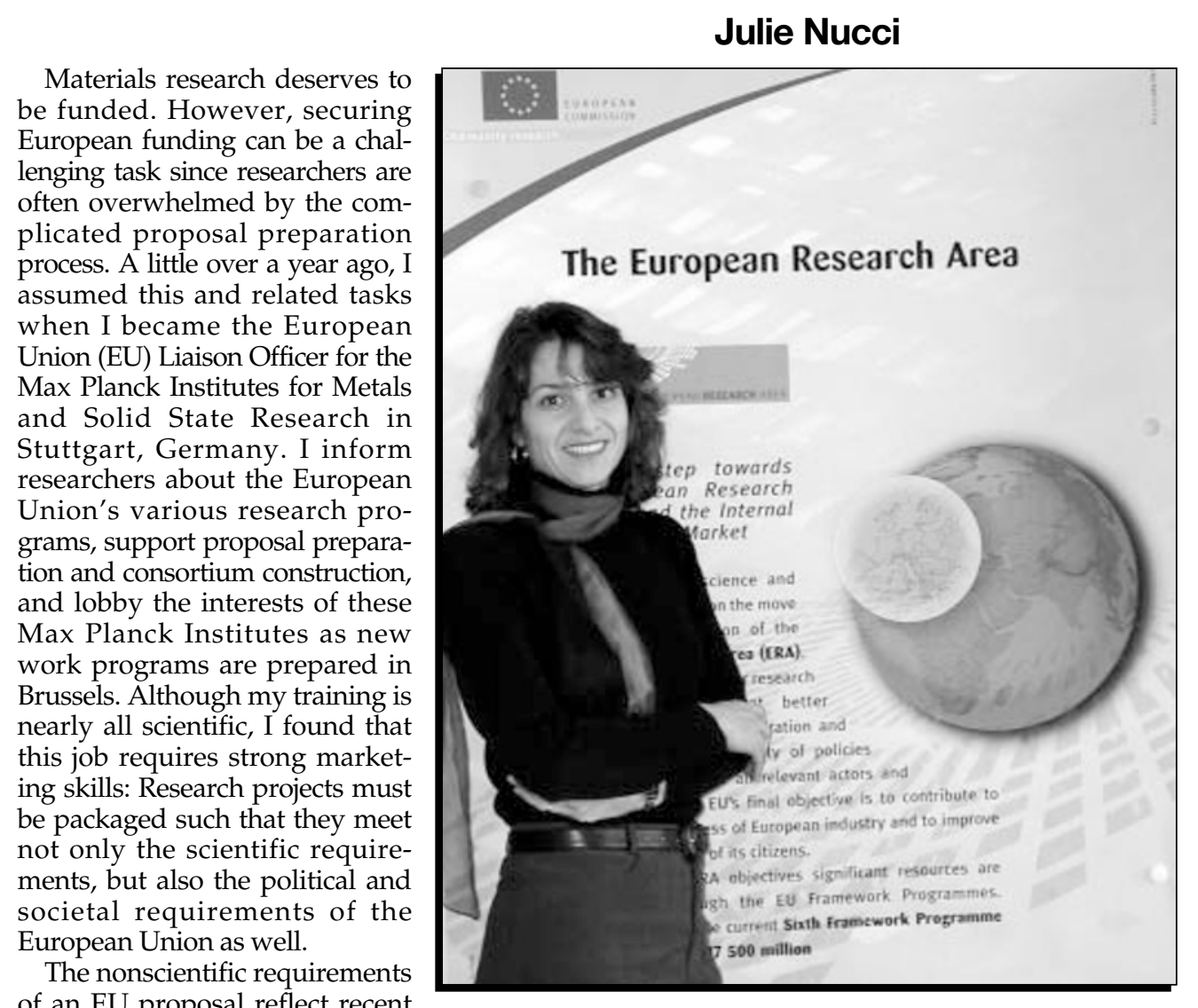

of an EU proposal reflect recent changes in European research policy. The European Research Area, launched at the Lisbon European Council in March 2000 , was created to unify science and technology policy across Europe. Main objectives of the 6th Framework Programme, which governs research funding from 2002 to 2006, include "strengthening the scientific and technological bases of Community industry," "the rapid establishment of a European research and innovation area with a view to sustainable economic growth, more employment and social cohesion," and "a structuring effect on research and technological development in Europe including member states, associated candidate countries, and third countries." With this in mind, it becomes clear why an EU proposal must include much more than science, and is therefore more complicated than a proposal for national-based funds.

In addition to an awareness of European politics and policies, communication, networking, and interpersonal skills are necessary in this position. I often work closely, one on one, with a project coordinator or consult to an entire consortium as the researchers develop their project plans. Effective dialogue with EU contacts and

Julie Nucci is the European Union (EU) Liaison Officer for the Max Planck Institutes for Metals and Solid State Research in Stuttgart, Germany.
German national representatives is important in order to receive early and "grey" information, understand critical factors for success, provide input into future research programs, and obtain assistance along the long road to proposal completion. While the combination of my Italian name, American accent, and German affiliation produces many confused looks, it is a great networking tool that provides an easy entrance into many useful conversations! Good writing skills are also a must. Interestingly, being an American is a real advantage when it comes to writing European proposals since the official proposal language is English.

Learning about new, exciting scientific fields is a great aspect of this job. Within the last year, I worked on projects related to nanomaterials, spintronics, advanced materials and processes for hydrogen storage and conversion for fuel-cell appli-

Career Clips explores the range of career possibilities in, or related to, materials science. the accurate restoration of historic Baroque and Medieval pipe organs. In addition, this past May I was selected as an Expert Evaluator for Specific Targeted Research Projects in Nanosciences. After spending a week in Brussels evaluating proposals, I gained significant insight into how a successful proposal is constructed and written. It was a great training opportunity and I strongly recommend that researchers take advantage of such evaluation opportunities. This is particularly useful for young researchers since it will likely improve their success rate for the many proposals ahead of them in their careers.

A career in materials can take on many forms. Mine began with a bachelor's degree in materials engineering from Rennselaer Polytechnic Institute and corporate positions as a CMOS process engineer at National Semiconductor Corporation and a failure analyst in the Semiconductor Acquisition and Test Division of Digital Equipment Corporation. Through the Graduate Engineering Education Program at Digital, I received a master's degree in applied physics from Harvard University. I continued the shift from engineering to science with a $\mathrm{PhD}$ degree in materials science from Cornell University. I have held a lecturing position in the Materials Science and Engineering Department at Cornell University and guest scientist positions at the Materials Reliability Division of the National Institute of Standards and Technology in Boulder, Colorado and the Max Planck Institute for Metals Research in Stuttgart, Germany. Now my career has again shifted, this time to an "alternative" path. As a researcher, I was well versed in a narrow research area, namely, the reliability of semiconductor metallization. As an EU Liaison Officer, I enjoy much broader exposure to materials and solidstate research, in addition to the opportunity to understand the impact of a growing Europe on research policy and funding. The EU offers many great funding opportunities for both people and projects. Knowing that I help researchers realize those opportunities and support topquality research at the Max Planck Institutes is a great source of job satisfaction. $\square$ 